\title{
gualidade de Sementes de Algodão Provenientes de Plantas Tratadas Com Doses Reduzidas de Glyphosate ${ }^{1}$
}

\author{
Quality of Cotton Seeds from Plants Submitted to Reduced Rates of Glyphosate \\ YAMASHITA, O.M. ${ }^{2}$ e GUIMARÃES, S.C. ${ }^{3}$
}

\begin{abstract}
RESUMO - O presente trabalho teve como objetivo avaliar a influência do tratamento de plantas de algodoeiro com doses reduzidas de glyphosate, simulando deriva, na qualidade das sementes produzidas. Plantas dos cultivares ITA-90 e BRS-Facual foram tratadas em dois diferentes estádios de desenvolvimento (quatro e dez folhas) com as doses de 0,180 e $360 \mathrm{~g} \mathrm{ha}^{-1}$ de glyphosate. Avaliaram-se o rendimento de algodão em caroço, a qualidade das sementes, através de massa de 100 sementes, a porcentagem de emergência e a massa seca de plântulas emersas. Houve redução no rendimento de algodão em caroço em todos os tratamentos, exceto em plantas mais velhas tratadas com $180 \mathrm{~g} \mathrm{ha}^{-1}$, sem afetar a qualidade das sementes.
\end{abstract}

Palavras-chave: Gossypium hirsutum, emergência, deriva, toxicidade.

\begin{abstract}
This work aimed to evaluate the influence of cotton plant treatment using reduced rates of glyphosate, simulating drift, on the quality of the seeds produced. The plants of the ITA90 and BRS-Facual cultivars were treated at two different development stages (4 and 10 leaves) with glyphosate in the doses of $0 ; 180$ and $360 \mathrm{~g} \mathrm{ha}^{-1}$ ea. Cotton crop yield was evaluated. The material was seeded and seed quality evaluated, through mass of 100 seeds, emergence percentage and mass of plantules. There was a reduction in cotton production in the treatments, except in older plants treated with $180 \mathrm{~g} \mathrm{ha}^{-1}$. No significant difference in plantule emergence was found in the different treatments.
\end{abstract}

Keywords: Gossypium hirsutum, emergence, drift, toxicity.

\section{INTRODUÇÃO}

A implementação de novas tecnologias agronômicas, como o sistema de plantio direto, proporcionou incremento no rendimento agronômico de diversas culturas. Dentre essas novas tecnologias, a utilização de herbicidas se tornou indispensável (Conceição, 2000), principalmente pela eficiência no manejo de plantas daninhas.

O glyphosate é um dos ingredientes ativos mais usados na dessecação da cobertura vegetal nesse sistema (Rodrigues \& Almeida, 1998; Puríssimo, 1999; Kruse et al., 2000;
Magalhães et al., 2001), e sua deriva se torna sério problema para culturas sensiveis (Banks \& Schroeder, 2002; Ellis et al., 2002; Lyon et al., 2003), como o algodoeiro, quando cultivadas próximo dessas áreas.

O conhecimento de sintomas e danos provocados pela deriva é necessário para auxiliar na identificação, na estimativa de perdas e na campanha para sua prevenção.

Além disso, a qualidade das sementes para formação de novas lavouras é um dos gargalos no processo produtivo (Freitas et al., 2000). Poucas são as pesquisas relacionadas aos

\footnotetext{
Recebido para publicação em 13.1.2006 e na forma revisada em 5.5.2006.

2 Eng.-Agrônomo, Doutorando em Agricultura Tropical pela FAMEV/UFMT. Professor do PCAA - UNEMAT - Universidade do Estado de Mato Grosso, Caixa postal 324, 78580-000 Alta Floresta-MT, <yama@ unemat.br>. ${ }^{3}$ Eng.-Agrônomo Dr., Professor da FAMEV - Universidade Federal de Mato Grosso - UFMT, Av. Fernando Correa da Costa, s/n, 78100-000 Cuiabá-MT, $<$ sheep@cpd.ufmt.br>.
}

Planta Daninha, Viçosa-MG, v. 24, n. 2, p. 353-358, 2006 
possiveis efeitos na qualidade fisiológica das sementes de plantas submetidas à deriva de herbicidas durante o seu processo de desenvolvimento.

Nesta pesquisa, objetivou-se estudar o efeito de doses reduzidas de glyphosate, simulando deriva, em diferentes estádios de desenvolvimento na qualidade de sementes produzidas por cultivares de algodoeiro.

\section{MATERIAL E MÉTODOS}

O ensaio no campo foi realizado em Latossolo Vermelho distrófico, cultivado durante dois anos com milho, em área experimental da Fazenda Yamashita, localizada no município de Alta Floresta-MT, a 0956’34" de latitude sul e 55 55'71" de longitude oeste, numa altitude de $334 \mathrm{~m}$. O clima da região, segundo a classificação de Köeppen, é do tipo Aw, ou seja, clima de savana, de outono/inverno seco.

Foi estudado o efeito do glyphosate, nas doses de 0,180 e $360 \mathrm{~g} \mathrm{ha}^{-1}$, sobre os cultivares ITA 90 e BRS-Facual, tratados nos estádios de quatro e dez folhas. Para cada cultivar, foram realizadas duas semeaduras, espaçadas de 20 dias (18.1.2003 e 8.2.2003), de forma a obter, numa única condição ambiental de aplicação de herbicida, plantas com idades de 20 e 40 dias.

A área foi preparada através de uma aração e duas gradagens, e as parcelas foram semeadas manualmente, sendo constituídas por quatro linhas de $4,0 \mathrm{~m}$ de comprimento e espaçadas $0,9 \mathrm{~m}$; por meio de desbaste, obtevese densidade final de 10 plantas por metro. A calagem foi realizada quatro meses antes da semeadura, conforme sugerido por Staut \& Kurihara (2001), elevando a saturação de bases para 60\%. A adubação foi estabelecida em função da análise de solo, conforme recomendação de pesquisa para a região (Fundação MT, 2001).

Foi utilizado o delineamento experimental de blocos casualizados, com quatro repetições, e os tratamentos foram constituídos pelo fatorial 3x2x2 (três doses de glyphosate, dois cultivares de algodoeiro e duas épocas de semeadura). A área útil da parcela foi representada pelas duas linhas centrais, eliminando-se 1,0 m de cada extremidade.
Na aplicação, foi utilizado um pulverizador costal manual, portando ponta de jato plano APG 110.01, com pressão constante de $440 \mathrm{kPa}$, mantida por $\mathrm{CO}_{2}$, calibrado para gasto de calda de $100 \mathrm{~L} \mathrm{ha}^{-1}$. Foi adicionado à calda do herbicida um espalhante adesivo contendo $200 \mathrm{~g} \mathrm{~L}^{-1}$ de nonil fenoxi poli (etilenoxi) etanol, na dose de 0,03\% v/v. Esse adjuvante foi acrescentado procurando compensar aqueles contidos na formulação comercial do herbicida, que seriam reduzidos pelo uso de subdosagens.

Atingindo o estádio de maturação, o algodão em caroço foi coletado por meio de colheitas manuais de todos os capulhos abertos.

O material foi levado para o Laboratório de Sementes da FAMEV (Faculdade de Agronomia e Medicina Veterinária) da Universidade Federal de Mato Grosso. As características avaliadas após a colheita foram:

Rendimento de algodão em caroço - Os capulhos abertos da área útil de cada parcela foram colhidos manualmente durante cinco semanas consecutivas. Após secagem ao ambiente, foi determinada a massa do material em balança de precisão $(0,1 \mathrm{~g})$, convertendo os valores em $\mathrm{kg} \mathrm{ha}^{-1}$.

Massa de 100 sementes, emergência e massa de plântulas - Avaliou-se, em três repetições, a massa de 100 sementes provenientes do ensaio no campo, previamente descaroçadas, que foram colocadas para germinar em areia esterilizada usando bandejas de plástico, sobre a bancada do laboratório, com a temperatura ambiente oscilando entre 25 e $31{ }^{\circ} \mathrm{C}$.

Foram utilizadas 50 sementes por bandeja de $26,5 \times 15,5 \times 7,5 \mathrm{~cm}$, preenchidas com substrato (areia) esterilizado, umedecido com água destilada até $70 \%$ de sua capacidade de retenção (Brasil, 1992).

A semeadura foi realizada a $2 \mathrm{~cm}$ de profundidade, e o reumedecimento do substrato foi feito sempre que necessário, procurandose manter as condições iniciais de umidade.

As avaliações consistiram da contagem das plântulas normais aos quatro e doze dias, determinando-se a massa do material fresco da parte aérea logo após cada avaliação, em balança semi-analítica com precisão de 0,01 g. 
Os dados coletados foram submetidos à análise de variância, comparando-se as médias das variáveis qualitativas, ou quantitativas com dois niveis, pelo teste de Scott \& Knott. Para análise estatística, os dados foram transformados em $\log \mathrm{x}$. Para a variável massa de 100 sementes, os dados obtidos foram transformados em porcentagem (\%) e comparados com a testemunha. Foi utilizado o nivel de 5\% de probabilidade.

\section{RESULTADOS E DISCUSSÃO}

Os resultados encontrados, a partir da análise estatística, são apresentados no quadro de análise de variância, com os respectivos quadrados médios e coeficiente de variação, na Tabela 1.

A massa de 100 sementes coletadas de plantas tratadas com subdoses de glyphosate foi influenciada pelo cultivar ( $p<0,01)$, pela dose de glyphosate $(\mathrm{p}<0,01)$, pelo estádio de desenvolvimento à época de aplicação ( $\mathrm{p}<0,01)$, pela interação entre cultivar e estádio de desenvolvimento $(\mathrm{p}<0,05)$, pela interação entre cultivar e dose de glyphosate ( $p<0,01)$ e pela interação estádio de desenvolvimento e dose de glyphosate $(\mathrm{p}<0,01)$.

Os resultados de massa de 100 sementes, expressos em porcentagem em relação à testemunha (dose de $0 \mathrm{~g} \mathrm{ha}^{-1}$ de glyphosate), são apresentados na Tabela 2 (cultivar x estádio de desenvolvimento), na Tabela 3 (cultivar x dose de glyphosate) e na Tabela 4 (estádio de desenvolvimento $\mathrm{x}$ dose de glyphosate).

O cultivar ITA-90, que apresentou maior suscetibilidade à deriva simulada de glyphosate quanto ao rendimento de algodão em caroço, teve também maior redução na massa das sementes produzidas quando comparado com o cultivar BRS-Facual. Em ambos os cultivares, a menor massa de sementes ocorreu quando a aplicação foi realizada no estádio de quatro folhas.

A aplicação da maior dose (360 $\mathrm{g} \mathrm{ha}^{-1}$ ) resultou em maior massa de grãos para os dois cultivares, com resposta diferencial para BRS-Facual, que apresentou massa de grãos superior a ITA-90, tanto na menor como na maior dose (Tabela 3).
Tabela 1 - Análise de variância dos dados relativos a massa de 100 sementes (M100S), emergência (EMER) e massa verde (MVER). Alta Floresta-MT, 2003

\begin{tabular}{|l|c|c|c|}
\hline \multirow{2}{*}{ Fonte de variação } & \multicolumn{3}{|c|}{ Quadrados médios } \\
\cline { 2 - 4 } & M100S & EMER & \multicolumn{1}{c|}{ MVER } \\
\hline Cultivar & $384.000^{*}$ & 0.003 & $2.278 .125^{*}$ \\
\hline Época & $334.507^{*}$ & $1.533 .195^{*}$ & 21.451 \\
\hline Dose & $59.535^{*}$ & 43.012 & $2.460 .511^{*}$ \\
\hline Cultivar*Época & $19.802^{*}$ & $2.497 .477^{*}$ & $11.773 .451^{*}$ \\
\hline Cultivar*Dose & $35.527^{*}$ & 0.227 & 98.701 \\
\hline Época*Dose & $29.927 *$ & $1.589 .070^{*}$ & 512.000 \\
\hline Cultivar*Época*Dose & 1.402 & 112.125 & 310.005 \\
\hline CV (\%) & 1,73 & 9,18 & 13,38 \\
\hline
\end{tabular}

* Significativo a 5\% de probabilidade pelo teste de Scott \& Knott.

Tabela 2 - Massa de 100 sementes, em \% em relação à testemunha, dos cultivares ITA-90 e BRS-Facual, provenientes de plantas tratadas com glyphosate nos estádios de quatro e dez folhas. Alta Floresta-MT, 2003

\begin{tabular}{|l|c|c|}
\hline \multirow{2}{*}{ Cultivar } & \multicolumn{3}{|c|}{ Estádio de desenvolvimento } \\
\cline { 2 - 3 } & 4 folhas & 10 folhas \\
\hline ITA-90 & $94,67 \mathrm{~B} \mathrm{~b}$ & $100,32 \mathrm{~B} \mathrm{a}$ \\
\hline BRS-FACUAL & $100,85 \mathrm{~A} \mathrm{~b}$ & $110,13 \mathrm{~A} \mathrm{a}$ \\
\hline
\end{tabular}

Médias que tenham em sua seqüência pelo menos uma letra em comum, maiúscula nas colunas e minúscula nas linhas, não diferem entre si pelo teste de Scott \& Knott a 5\% de probabilidade.

Tabela 3 - Massa de 100 sementes, em \% em relação à testemunha, dos cultivares ITA-90 e BRS-Facual, provenientes de plantas tratadas com 180 e $360 \mathrm{~g} \mathrm{ha}^{-1}$ de glyphosate. Alta Floresta-MT, 2003

\begin{tabular}{|l|c|c|}
\hline \multirow{2}{*}{ Cultivar } & \multicolumn{2}{|c|}{ Dose de glyphosate $\left(\mathrm{g} \mathrm{ha}^{-1}\right)$} \\
\cline { 2 - 3 } & 180 & 360 \\
\hline ITA-90 & $94,70 \mathrm{~B} \mathrm{~b}$ & $100,28 \mathrm{~B} \mathrm{a}$ \\
\hline BRS-FACUAL & $105,13 \mathrm{~A} \mathrm{a}$ & $105,85 \mathrm{~A} \mathrm{a}$ \\
\hline
\end{tabular}

Médias que tenham em sua sequiência pelo menos uma letra em comum, maiúscula nas colunas e minúscula nas linhas, não diferem entre si pelo teste de Scott \& Knott a 5\% de probabilidade.

Plantas com quatro folhas tratadas com $360 \mathrm{~g} \mathrm{ha}^{-1}$ de glyphosate apresentaram maior massa relativa de grãos que quando tratadas com $180 \mathrm{~g} \mathrm{ha}^{-1}$; contudo, quando tratadas em estádio de dez folhas, não houve diferença entre doses. 
Comparando os dois estádios de desenvolvimento, observou-se que plantas submetidas ao herbicida em estádio de dez folhas apresentaram maior massa de grãos, sem diferença entre doses (Tabela 4).

Aumentos observados na massa de 100 sementes podem ser explicados pelo fato de que, na dose mais alta de glyphosate, houve menor rendimento de algodão em caroço (dados não apresentados), podendo ter sido conseqüência do menor número de capulhos por planta. Esse menor número de capulhos poderia ter favorecido a maior massa de grãos.

A emergência de plântulas originárias de sementes provenientes de plantas submetidas a subdoses de glyphosate foi influenciada pelo estádio de desenvolvimento ( $\mathrm{p}<0,01)$, pela interação entre cultivar e estádio de desenvolvimento $(p<0,01)$ e pela interação entre estádio de desenvolvimento e doses de glyphosate $(\mathrm{p}<0,01)$. A massa da matéria fresca dessas plântulas foi influenciada pelo cultivar $(p<0,05)$, pela dose de glyphosate $(p<0,01)$ e pela interação entre cultivar e estádio de desenvolvimento das plantas $(\mathrm{p}<0,01)$.

Os resultados de emergência de plântulas (\% em relação à testemunha) estão apresentados na Tabela 5 (estádio de desenvolvimento $\mathrm{x}$ cultivar) e na Tabela 6 (estádio de desenvolvimento e dose de glyphosate). A massa das plântulas é mostrada na Tabela 7 (efeito da dose) e na Tabela 8 (estádio de desenvolvimento $\mathrm{x}$ cultivar).

Em todos os resultados, observa-se que a emergência de plântulas foi muito próxima ou superior aos valores encontrados na testemunha (valor relativo de 100).

Quando as sementes do cultivar ITA-90 foram originadas de plantas tratadas com glyphosate em estádio de quatro folhas, estas apresentaram emergência de plântulas 31\% maior que no estádio de dez folhas. Para o cultivar BRS-Facual não houve diferença entre estádios de desenvolvimento (Tabela 5).

A menor dose de glyphosate apresentou maior porcentagem de emergência de plântulas que a maior dose quando as plantas foram tratadas em estádio de quatro folhas. Contudo, quando as plantas com dez folhas foram tratadas com o herbicida, observou-se resultado contrário. Avaliando-se estádios de desenvolvimento, plantas com quatro folhas tratadas com $180 \mathrm{~g} \mathrm{ha}^{-1}$ apresentaram emergência 28\% maior que quando tratadas com dez folhas. Na dose de $360 \mathrm{~g} \mathrm{ha}^{-1}$, não se observou diferença entre estádios de desenvolvimento (Tabela 6).

Sementes produzidas por plantas de algodoeiro que receberam aplicações de subdoses

Tabela 4 - Massa de 100 sementes de algodoeiro (\% em relação à testemunha) de plantas tratadas com 180 e $360 \mathrm{~g} \mathrm{ha}^{-1}$ de glyphosate nos estádios de quatro e dez folhas. Alta Floresta-MT, 2003

\begin{tabular}{|c|c|c|}
\hline \multirow{2}{*}{$\begin{array}{c}\text { Estádio de } \\
\text { desenvolvimento }\end{array}$} & \multicolumn{2}{|c|}{ Dose de glyphosate $\left(\mathrm{g} \mathrm{ha}^{-1}\right)$} \\
\cline { 2 - 3 } & 180 & 360 \\
\hline 4 folhas & $95,07 \mathrm{~B} \mathrm{~b}$ & $100,45 \mathrm{~B} \mathrm{a}$ \\
\hline 10 folhas & $104,77 \mathrm{~A} \mathrm{a}$ & $105,68 \mathrm{~A} \mathrm{a}$ \\
\hline
\end{tabular}

Médias que tenham em sua seqüência pelo menos uma letra em comum, maiúscula nas colunas e minúscula nas linhas, não diferem entre si pelo teste de Scott \& Knott a 5\% de probabilidade.

Tabela 5 - Emergência de plântulas dos cultivares ITA-90 e BRS-Facual originárias de sementes de plantas tratadas com glyphosate nos estádios de quatro e dez folhas $(\% \mathrm{em}$ relação à testemunha). Alta Floresta-MT, 2003

\begin{tabular}{|l|c|c|}
\hline \multirow{2}{*}{ Cultivar } & \multicolumn{2}{|c|}{ Estádio de desenvolvimento } \\
\cline { 2 - 3 } & 4 folhas & 10 folhas \\
\hline ITA-90 & $97,43 \mathrm{~B} \mathrm{~b}$ & $128,93 \mathrm{~A} \mathrm{a}$ \\
\hline BRS-FACUAL & $115,08 \mathrm{~A} \mathrm{a}$ & $111,25 \mathrm{~A} \mathrm{~b}$ \\
\hline
\end{tabular}

Médias que tenham em sua seqüência pelo menos uma letra em comum, maiúscula nas colunas e minúscula nas linhas, não diferem entre si pelo teste de Scott \& Knott a 5\% de probabilidade.

Tabela 6 - Emergência de plântulas de algodoeiro originárias de sementes de plantas tratadas com 180 e $360 \mathrm{~g} \mathrm{ha}^{-1}$ de glyphosate nos estádios de quatro e dez folhas $(\% \mathrm{em}$ relação à testemunha). Alta Floresta-MT, 2003

\begin{tabular}{|c|c|c|}
\hline \multirow{2}{*}{$\begin{array}{c}\text { Estádio de } \\
\text { desenvolvimento }\end{array}$} & \multicolumn{2}{|c|}{ Dose de glyphosate $\left(\mathrm{g} \mathrm{ha}^{-1}\right)$} \\
\cline { 2 - 3 } & 180 & 360 \\
\hline 4 folhas & $128,00 \mathrm{~A} \mathrm{a}$ & $112,14 \mathrm{~A} \mathrm{~b}$ \\
\hline 10 folhas & $100,36 \mathrm{~B} \mathrm{~b}$ & $111,89 \mathrm{~A} \mathrm{a}$ \\
\hline
\end{tabular}

Médias que tenham em sua seqüência pelo menos uma letra em comum, maiúscula nas colunas e minúscula nas linhas, não diferem entre si pelo teste de Scott \& Knott a 5\% de probabilidade. 
de glyphosate, de modo geral, não tiveram redução na emergência nem na massa de plântulas. De modo contrário, em algumas combinações de doses e estádios de desenvolvimento ocorreu aumento nessas características (Tabelas 5 e 6). Assim, os prejuízos decorrentes da deriva se manifestam pela redução na quantidade e não na qualidade das sementes produzidas.

Plantas tratadas com $360 \mathrm{~g} \mathrm{ha}^{-1} \mathrm{de}$ glyphosate geraram sementes cuja massa verde de plântulas foi $28 \%$ superior à daquelas que receberam a dose de $180 \mathrm{~g} \mathrm{ha}^{-1}$ (Tabela 7).

A aplicação de glyphosate provocou alterações na massa verde de plântulas originadas de sementes dessas plantas, com resultado diferencial para cada cultivar e estádio de desenvolvimento no momento da aplicação (Tabela 8).

O cultivar ITA-90 apresentou massa verde de plântulas $40 \%$ maior quando o tratamento foi realizado no estádio de quatro folhas. Entretanto, resultado oposto foi observado no

Tabela 7 - Massa verde de plântulas de algodoeiro originárias de sementes de plantas tratadas com 180 e $360 \mathrm{~g} \mathrm{ha}^{-1}$ de glyphosate (\% em relação à testemunha). Alta FlorestaMT, 2003

\begin{tabular}{|c|c|}
\hline $\begin{array}{c}\text { Dose de glyphosate } \\
\left(\mathrm{g} \mathrm{ha}^{-1}\right)\end{array}$ & Massa verde \\
\hline 180 & $124,96 \mathrm{~B}$ \\
\hline 360 & $142,49 \mathrm{~A}$ \\
\hline
\end{tabular}

Médias que tenham em sua seqüência pelo menos uma letra em comum não diferem entre si pelo teste de Scott \& Knott a 5\% de probabilidade.

Tabela 8 - Massa verde dos cultivares ITA-90 e BRS-Facual originários de sementes de plantas tratadas com glyphosate nos estádios de quatro e dez folhas (\% em relação à testemunha). Alta Floresta-MT, 2003

\begin{tabular}{|l|c|c|}
\hline \multirow{2}{*}{ Cultivar } & \multicolumn{2}{|c|}{ Estádio de desenvolvimento } \\
\cline { 2 - 3 } & 4 folhas & 10 folhas \\
\hline ITA-90 & $162,16 \mathrm{~A} \mathrm{a}$ & $122,16 \mathrm{~B} \mathrm{~b}$ \\
\hline BRS-FACUAL & $106,93 \mathrm{~B} \mathrm{~b}$ & $143,65 \mathrm{~A} \mathrm{a}$ \\
\hline
\end{tabular}

Médias que tenham em sua seqüência pelo menos uma letra em comum, maiúscula nas colunas e minúscula nas linhas, não diferem entre si pelo teste de Scott \& Knott a 5\% de probabilidade. cultivar BRS-Facual, em que plântulas provenientes de sementes coletadas de plantas tratadas com glyphosate em estádio de dez folhas produziram massa verde $36 \%$ maior que em estádio de quatro folhas.

Houve resposta diferencial entre os cultivares dentro de cada estádio de desenvolvimento, em que ITA-90 apresentou maior massa verde de plântulas que BRS-Facual, tratados com glyphosate no estádio de quatro folhas. Entretanto, no estádio de dez folhas, BRS-Facual apresentou massa verde de plântulas 21\% superior à de plântulas do cultivar ITA-90.

A emergência correlacionou-se positivamente com a massa de plântulas ( $\mathrm{r}=0,551$; $\mathrm{p}<0,01$ ), resultado esperado, pois o maior número de plântulas emergidas proporcionou maior massa final de plântulas. A massa de sementes também se correlacionou positivamente com a massa de plântulas $(\mathrm{r}=0,402$; $\mathrm{p}<0,01$ ), podendo isso estar ligado ao fato de que sementes com maior massa apresentam maior viabilidade de germinação, o que conseqüentemente geraria plântulas mais saudáveis e mais pesadas (Tabela 9).

Tabela 9 - Coeficientes de correlação entre massa de 100 sementes (M100s), emergência (EMG) e massa verde de plântulas (MPL) provenientes de sementes de algodoeiro tratado com 180 e $360 \mathrm{~g} \mathrm{ha}^{-1}$ de glyphosate. Alta FlorestaMT, 2003

\begin{tabular}{|c|c|c|}
\hline Coeficiente de correlação & EMG & MPL \\
\hline M100s & 0,202 & $0,402^{* *}$ \\
\hline EMG & --- & $0,551^{* *}$ \\
\hline
\end{tabular}

**significativo a $1 \%$ de probabilidade.

De acordo com os resultados, a análise das características das sementes (massa das sementes, emergência e massa de plântulas) indica que esses propágulos não sofrem reduções em função do tratamento das plantas com subdoses de glyphosate, podendo, em alguns casos, ocorrer aumento nos valores desses atributos.

\section{LITERATURA CITADA}

BANKS, P. A.; SCHROEDER, J. Carrier volume affects herbicide activity in simulated spray drift studies. Weed Technol., v. 16, p. 833-837, 2002. 
BRASIL. Ministério da Agricultura e Reforma Agrária. Regras para análise de sementes. Brasília: SNAD/CLAV, 1992. $365 \mathrm{p}$.

CONCEIÇÃO, M. Z. Segurança na aplicação de herbicidas. In: CONGRESSO BRASILEIRO DA CIÊNCIA DAS

PLANTAS DANINHAS, 22., 2000, Foz do Iguaçu.

Palestras... Foz do Iguaçu: Sociedade Brasileira da Ciência das Plantas Daninhas, 2000. p. 46-91.

ELLIS, J. M.; GRIFFIN, J. L.; JONES, C. A. Effect of carrier volume on corn (Zea mays) and soybean (Glycine max) response to simulated drift of glyphosate and glufosinate. Weed Technol., v. 16, p. 587-592, 2002.

FREITAS, R. A. e al. Correlação entre testes para avaliação da quantidade de sementes de algodão e a emergência das plântulas a campo. R. Bras. Sementes, v. 22, p. 97-103, 2000.

FUNDAÇÃO MT. Boletim de pesquisa de algodão. Rondonópolis: 2001. 225 p. (Boletim, 4).
KRUSE, N. D.; TREZZI, M. M.; VIDAL, R. A. Herbicidas inibidores da EPSPs: revisão de literatura. R. Bras. Herbic. v. 1, p. 139-146, 2000.

LYON, L.L. et al. Sorghum response to simulated drift rates of glyphosate. Proceedings... Alabama: Southern Weed Science Society, 2003. v. 56. p. 273.

MAGALHÃES, P. C. et al. Efeito de doses reduzidas de glyphosate e paraquat simulando deriva na cultura do milho. Planta Daninha, v. 19, n. 2, p. 247-253, 2001.

PURÍSSIMO, C. Classificação de herbicidas quanto ao mecanismo de ação. In: SEMINÁRIO SOBRE SISTEMA DE PLANTIO DIRETO DA UFV, 2., 1999, Viçosa. Anais... Viçosa, MG: UFV, 1999. p. 73-110.

RODRIGUES, B. N.; ALMEIDA, F. S. Guia de herbicidas. 4.ed. Londrina: IAPAR, 1998. 648 p.

STAUT, L. A.; KURIHARA, C. H. Calagem e adubação. In: Embrapa Agropecuária Oeste; Embrapa Algodão. Algodão: tecnologia de produção. Dourados: Embrapa Agropecuária Oeste, 2001. p. 103-123. 